\title{
Hydroxyapatite: a promising hemostatic component in orthopaedic applications
}

\author{
Yin Yang ${ }^{1,2}$, Huan Zhou ${ }^{1,3 *}$, Xinye $\mathrm{Ni}^{4}$, Mengmeng Yang ${ }^{1,2}$, Saisai Hou ${ }^{1,3}$, Yaping $\mathrm{Bi}^{1,2}$ and Linhong Deng ${ }^{1 *}$ \\ ${ }^{1}$ Institute of Biomedical Engineering and Health Sciences, Changzhou University, Changzhou, Jiangsu 213164, China \\ ${ }^{2}$ School of Pharmaceutical Engineering and Life Science, Changzhou University, Changzhou, Jiangsu 213164, China \\ ${ }^{3}$ International Research Centre for Translational Orthopedics (IRCTO), Suzhou, Jiangsu 215006, China \\ ${ }^{4}$ Second People's Hospital of Changzhou, Nanjing Medical University, Changzhou, Jiangsu 213003, China \\ ${ }^{5}$ School of Materials Science and Engineering, Changzhou University, Changzhou, Jiangsu 213164, China
}

\begin{abstract}
Agent with both great blood clotting activity and bone regeneration ability is deserved to replace conventional bone wax. Recently, hydroxyapatite (HA) has attracted interests from researchers with its both hemostatic and bone healing functions. In present work, the blood clotting activity comparisons of HA to other potential bone repairing materials including calcium silicate, calcium combined attapulgite, calcium tripolyphosphate, and chitosan were carried out to show $\mathrm{HA}$ as a recommended hemostatic component to replace bone wax. In addition, the impacts of HA synthesis routes on its blood clotting activity were evaluated, indicating increase of surface area as well as active $\mathrm{Ca}^{2+}$ of $\mathrm{HA}$ can greatly enhance blood clotting. With these attributes, it is expected HA can be a promising component in fabricating hemostatic materials in orthopedic applications as alternatives to bone wax.
\end{abstract}

\section{Introduction}

Hemostatic agent is critical for successful clinical outcomes in bone defects surgery. Conventionally, beeswax-based bone wax has been used as hemostatic agent. But it is challenged for its poor biodegradation and biocompatibility [1]. Potential alternative hemostatic candidates in orthopedic surgery include both natural polymers such as collagen, cellulose, gelatin etc. and inorganic materials such as zeolite, clays, and silica. However, these materials may have different problems for clinical practice. For example, as shown in a current spinal surgery study on rats, hemostatic polymers may cause undesirable complications such as inflammation and fibrosis [2]. On the other hand, the inorganic materials may be associated with non-biocompatible and/or nonbiodegradable nature, as well as hydration related thermal issue $[3,4]$.

In principle, an ideal hemostatic agent for orthopedic applications should not only be able to stop bleeding but also promote bone healing. Recently, hydroxyapatite $\left(\mathrm{HA}, \mathrm{Ca}_{10}\left(\mathrm{PO}_{4}\right)_{6}(\mathrm{OH})_{2}\right)$ has attracted interests from researchers because of its hemostatic properties, besides its more well-known bone healing function [5,6]. Initially HA was combined with hemostatic polymers to improve their limited osteoconductivity. For example, Hoffmann fabricated a HA/starch/chitosan composite hemostatic material, proposed to be a substitute for bone wax or even as a bone filling material for orthopedic surgery applications [7]. After that, researcher noticed the presence of HA not only improve the composite's bone regeneration ability, but also enhance its blood clotting activity. Maruyama et al. combined HA with agarose gel and reported the presence of HA can greatly induce activation of blood coagulation and platelets aggregation compared to HA or agarose alone [8]. While Song et al. deposited HA to porous PLGA microspheres and the blood clotting activity was improved in the order of HA content increase [5]. Researchers have suggested blood clotting activity of HA is attributed to its high affinity with plasma proteins such as fibrinogen, and released $\mathrm{Ca}^{2+}$ [8]. Unfortunately, few fundamental studies have been carried out to evaluate the blood clotting activity of HA in comparison to other potential bone repairing materials to highlight its significance as a hemostatic agent in orthopaedic applications. Meanwhile, it is also unclear whether the synthesis routes of HA have impacts on its blood clotting activity. Therefore, in current work we report experimental results of blood clotting activity comparisons of 1) calcium based inorganic bone repairing materials including $\mathrm{HA}$, calcium silicate $\left(\mathrm{CaSiO}_{3}\right)$, calcium combined attapulgite (Ca-attapulgite, $\left.\mathrm{Ca}-(\mathrm{Mg}, \mathrm{Al})_{2} \mathrm{Si}_{4} \mathrm{O}_{10}(\mathrm{OH}) \cdot 4\left(\mathrm{H}_{2} \mathrm{O}\right)\right)$, and calcium tripolyphosphate $\left.\left(\mathrm{Ca}_{5}\left(\mathrm{P}_{3} \mathrm{O}_{10}\right)_{2}\right) ; 2\right) \mathrm{HA}$ and hemostatic polymers such as chitosan; 3) HA synthesized following different approaches.

\section{Material and methods}

Chemicals were purchased from Aladdin China if not specified. HA was hydrothermally synthesized in an autoclave using $\mathrm{Ca}(\mathrm{OH})_{2}$ and $\mathrm{Na}_{2} \mathrm{HPO}_{4}$ as reported by our group [9]. Generally, an amount of $0.37 \mathrm{~g}$ of $\mathrm{Ca}(\mathrm{OH})_{2}$ was mixed with $300 \mathrm{~mL}$ of distilled water to make a suspension. Then $0.71 \mathrm{~g} \mathrm{Na}_{2} \mathrm{HPO}_{4}$ was added to react with $\mathrm{Ca}(\mathrm{OH})_{2}$. The prepared liquid mixture was magnetically stirred for $15 \mathrm{~min}$. The

Correspondence to: Huan Zhou, Institute of Biomedical Engineering and Health Sciences, Changzhou University, Changzhou, China, Tel: (86)0519-86330103; E-mail: huanzhou@cczu.edu.cn

Linhong Deng, Institute of Biomedical Engineering and Health Sciences, Changzhou University, Changzhou, China, Tel: (86)0519-86330988; E-mail: dlh@cczu.edu.cn

Key words: hydroxyapatite, hemostatic agent, bone, blood clotting

Received: January 02, 2017; Accepted: January 11, 2017; Published: January 14 2017 
$\mathrm{pH}$ value of the liquid mixture was kept at 10 using $1 \mathrm{M} \mathrm{NaOH}$ solution. The mixtures were hydrothermally treated in an autoclave for 4hours to obtain $\mathrm{HA} . \mathrm{CaSiO}_{3}$ was precipitated via the reaction of tetraethyl

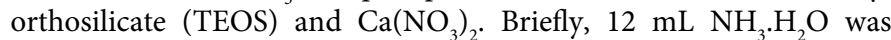
dissolved in $600 \mathrm{~mL}$ distilled $\mathrm{H}_{2} \mathrm{O}$ with stirring for $30 \mathrm{~min}$. Then, $30 \mathrm{~mL}$ TEOS and $31.21 \mathrm{~g} \mathrm{Ca}\left(\mathrm{NO}_{3}\right)_{2} \cdot 4 \mathrm{H}_{2} \mathrm{O}$ were added with vigorous stirring for 3 hours. The products were collected by filtration and washed three times each with distilled $\mathrm{H}_{2} \mathrm{O}$ and ethanol. Ca-attapulgite was prepared using attapulgite purchased from Zijin Mining, China. The powders were treated by 24 hours acidification using $6 \mathrm{M} \mathrm{HCl}$ followed by 24 hrs $1 \mathrm{M} \mathrm{CaCl}$ incubation with stirring. Meanwhile $\mathrm{Ca}_{5}\left(\mathrm{P}_{3} \mathrm{O}_{10}\right)_{2}$ was formed by complexation of $1.11 \mathrm{~g} \mathrm{CaCl}_{2}$ and $0.123 \mathrm{~g} \mathrm{Na}_{5} \mathrm{P}_{3} \mathrm{O}_{10}$ (STPP) in $100 \mathrm{~mL} \mathrm{H} \mathrm{H}_{2} \mathrm{O}$ with continued stirring for $30 \mathrm{~min}$. All as prepared powders were characterized using X-ray diffraction (XRD, Rigaku) and transmission electron microscope (TEM, Zeiss).

The blood clotting activity was in vitro measured as blood clotting index (BCI) [10]. Human blood in addition with the anticoagulant citrate dextrose (ACD) (9:1) was used for testing, referred as ACDwhole blood. This blood was kindly provided by Changzhou No.2 People's Hospital. In brief, $0.09 \mathrm{~g}$ of powder was used to contact with $0.27 \mathrm{~mL}$ blood sample $(0.3 \mathrm{~mL}$ ACD-whole blood by addition of 0.024 $\left.\mathrm{ml} \mathrm{CaCl}_{2}(0.2 \mathrm{~mol} / \mathrm{L})\right)$ at $37^{\circ} \mathrm{C}$ for $10 \mathrm{~min}$. The free blood was collected and diluted into $50 \mathrm{~mL}$ for spectrophotometric measurement at 542 $\mathrm{nm}$. The absorbance of $0.25 \mathrm{~mL}$ ACD-whole blood in $50 \mathrm{~mL}$ deionized water at $542 \mathrm{~nm}$ was applied as a reference value. The BCI can be quantified by the following equation:

$B C I$ index $=\frac{100 \times(\text { abs of blood which had been in contact with sample at } 542 \mathrm{~nm})}{\text { abs of } A C D-\text { whole blood in water at } 542 \mathrm{~nm}}$

Powders of chitosan, HA and a mixture of both (1:1) were used for BCI testing. Besides, considering HA can be combined with chitosan to fabricate biomimetic bone scaffold [11], comparison between porous chitosan scaffold and HA coated one was also carried out. $600 \mu \mathrm{L}$ of $0.015 \mathrm{~g} / \mathrm{mL}$ chitosan solution in well was freeze dried into porous scaffold, which was further incubated into $37^{\circ} \mathrm{C} 1.5 \mathrm{x}$ t-simulated body fluid (t-SBF) for 7 days with solution replenished every $48 \mathrm{hrs}$ to deposit HA coatings (Table 1). The surface change of chitosan scaffold after SBF incubation was characterized using scanning electron microscope (SEM, Zeiss). The $\mathrm{t}$-SBF is a Tris $\left(\mathrm{C}_{4} \mathrm{H}_{11} \mathrm{NO}_{6}\right)$ buffered SBF solution developed by Tas and Bhaduri, closely mimicking the composition of human blood plasma [12]. In present work, the ionic concentrations of $\mathrm{t}-\mathrm{SBF}$ solution were intensified 1.5times to accelerate HA coating formation. BCI index and the swelling ability of scaffolds in phosphate buffer (PBS) were measured. The swelling ratio of the scaffold at a given time $(t), Q_{t}$, can be calculated using equation below, where $m_{0}$ and $m_{t}$ are the weights of the dried and swollen scaffold, and $Q_{t}$ is calculated as grams of water per gram of scaffold.

Table 1. Compositions of 1L 1.5x t-SBF.

\begin{tabular}{|c|c|c|}
\hline Order & Reagent & Amount \\
\hline 1 & $\mathrm{NaCl}$ & $9.8184 \mathrm{~g}$ \\
\hline 2 & $\mathrm{NaHCO}_{3}$ & $3.4023 \mathrm{~g}$ \\
\hline 3 & $\mathrm{KCl}$ & $0.5591 \mathrm{~g}$ \\
\hline 4 & $\mathrm{Na}_{2} \mathrm{HPO}_{4}$ & $0.2129 \mathrm{~g}$ \\
\hline 5 & $\mathrm{MgCl}_{2} \cdot 6 \mathrm{H}_{2} \mathrm{O}$ & $0.4574 \mathrm{~g}$ \\
\hline 6 & $1 \mathrm{M} \mathrm{HCL}$ & $15 \mathrm{~mL}$ \\
\hline 7 & $\mathrm{CaCl}_{2} \cdot 2 \mathrm{H}_{2} \mathrm{O}$ & $0.5822 \mathrm{~g}$ \\
\hline 8 & $\mathrm{Na}_{2} \mathrm{SO}_{4}$ & $0.1080 \mathrm{~g}$ \\
\hline 9 & $\mathrm{Tris}_{4}-\mathrm{Base}$ & $9.0945 \mathrm{~g}$ \\
\hline 10 & $1 \mathrm{M} \mathrm{HCl}$ & $50 \mathrm{~mL}$ \\
\hline
\end{tabular}

$$
Q_{t}=\frac{100 \times\left(m_{t}-m_{0}\right)}{m_{0}}
$$

The third part was the study of clotting activity of HA synthesized following different approaches. Sodium hexametaphosphate $\left(\mathrm{Na}_{6} \mathrm{P}_{6} \mathrm{O}_{18}\right.$, SHMP), were used to prepare mesoporous HA (HA-HMP) to show the increase of surface area can promote clotting [9]. On the other hand, precipitates (HA-1) from the solution of $11.1 \mathrm{~g} / \mathrm{L} \mathrm{CaCl}_{2}$ and $1.56 \mathrm{~g} / \mathrm{L}$ $\mathrm{NaH}_{2} \mathrm{PO}_{4} \cdot 2 \mathrm{H}_{2} \mathrm{O}$ were studied to show whether increase of $\mathrm{Ca} / \mathrm{P}$ can have significant influence on related blood clotting activity. The XRD and TEM characterizations of these powders were also carried out.

\section{Results and discussion}

The XRD patterns of as-prepared Ca containing inorganic salts are shown in Figure 1. All powders displayed the characteristics of expected phases. According to the XRD, the synthesized HA and Caattapulgite matched the profiles in Jade (PDF \# 09-0432 and 20-0958) respectively. While the as-prepared $\mathrm{CaSiO}_{3}$ and $\mathrm{Ca}_{5}\left(\mathrm{P}_{3} \mathrm{O}_{10}\right)_{2}$ were mainly amorphous, like reported before [13,14]. The TEM results of these particles are presented in Figure 2. It was seen that the $\mathrm{HA}, \mathrm{CaSiO}_{3}$, $\mathrm{Ca}$-attapulgite and $\mathrm{Ca}_{5}\left(\mathrm{P}_{3} \mathrm{O}_{10}\right)_{2}$ present rod-like, spherical, whisker-

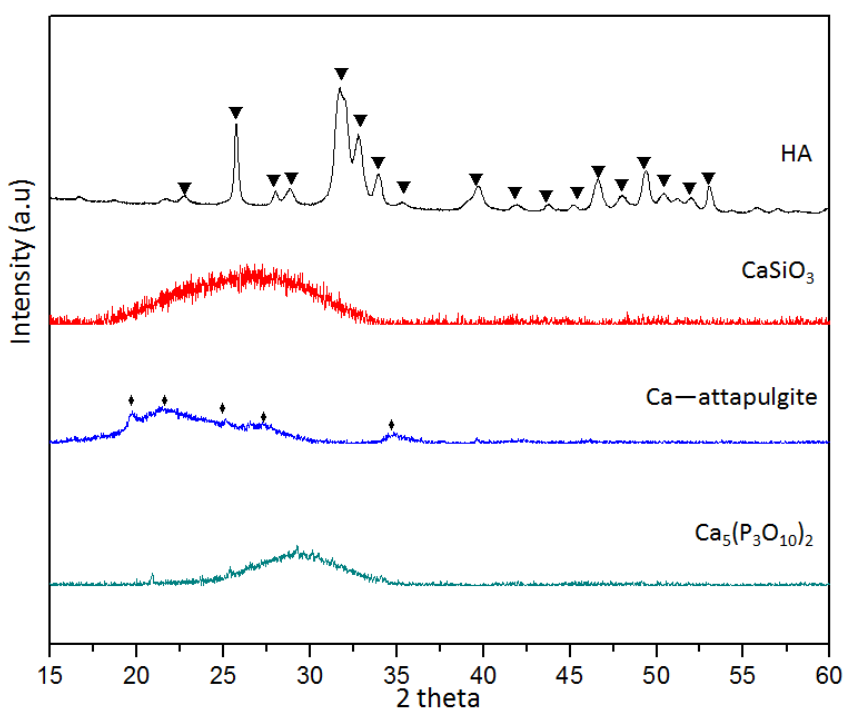

Figure 1. XRD patterns of tested calcium contained inorganic salts, " $\nabla$ "refers to HA and " $\bullet$ refers to attapulgite

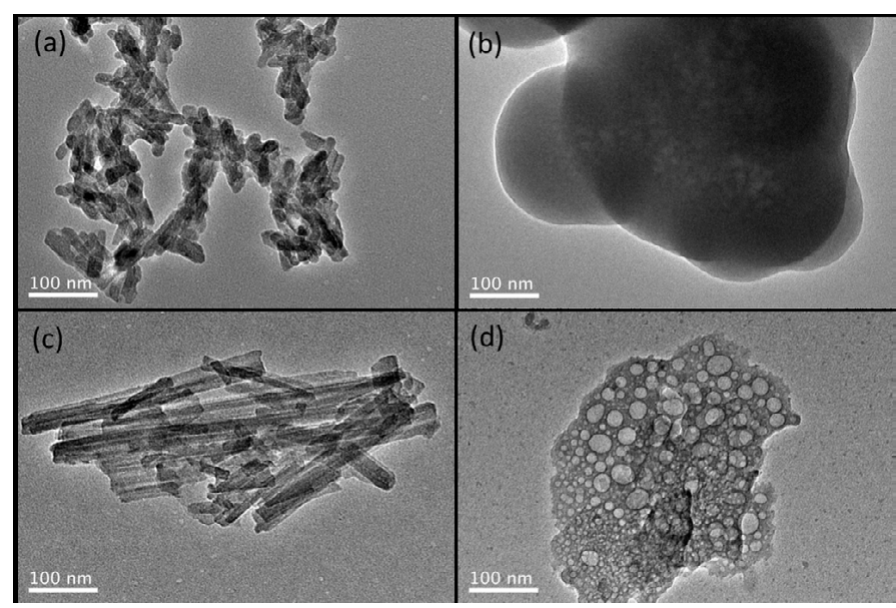

Figure 2. TEM images of (a) $\mathrm{HA}$, (b) $\mathrm{CaSiO}_{3}$, (c) Ca-attapulgite, (d) $\mathrm{Ca}_{5}\left(\mathrm{P}_{3} \mathrm{O}_{10}\right)_{2}$ 


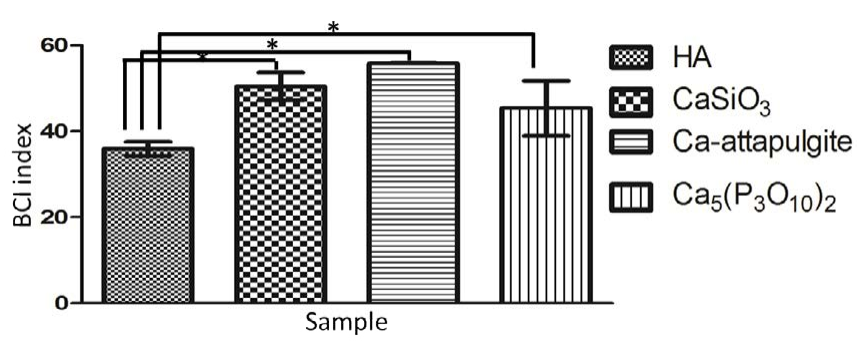

Figure 3. $\mathrm{BCI}$ index results of $\mathrm{HA}, \mathrm{CaSiO}_{3}$, Ca-attapulgite, and $\mathrm{Ca}_{5}\left(\mathrm{P}_{3} \mathrm{O}_{10}\right)_{2}$ (“*” indicates $\mathrm{p}<0.05$ ).

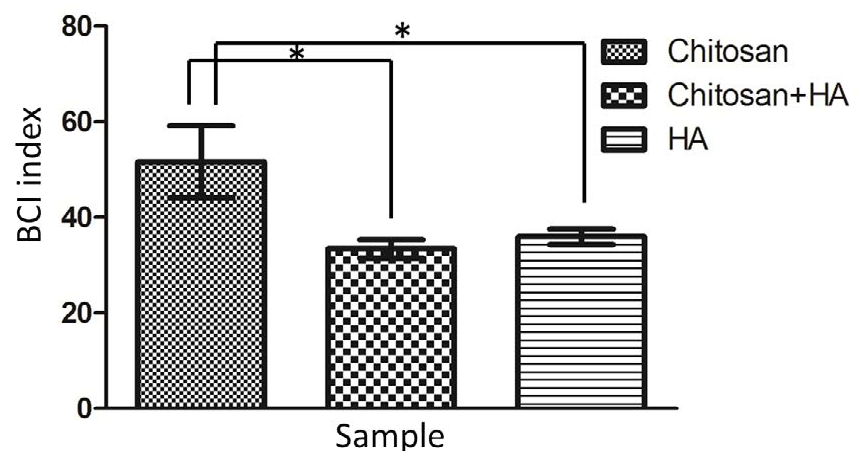

Figure 4. BCI index results of HA, chitosan and a mixture of HA and chitosan.

like and mesoporous morphology respectively. Among these materials, $\mathrm{CaSiO}_{3}$ was commonly studied as an alternative to $\mathrm{HA}$ for bone repairing [15]. Additionally, it also showed ability to absorb proteins like HA [16]. Therefore, it is necessary to compare the hemostatic ability of $\mathrm{HA}$ and $\mathrm{CaSiO}_{3}$, thus indicting the reason choosing $\mathrm{HA}$ as the potential hemostatic agent instead of $\mathrm{CaSiO}_{3}$. Attapulgite was another silicate material highlighted with its absorption ability and bone repairing potential [17]. The incorporation of $\mathrm{Ca}^{2+}$ to attapulgite was supposed to enhance its clotting activity. Meanwhile, the reason choosing $\mathrm{Ca}_{5}\left(\mathrm{P}_{3} \mathrm{O}_{10}\right)_{2}$ was attributed to the report that polyphosphate can accelerate blood clotting [18] and its self-assembled porous structure [13]. Per the BCI results (Figure 3), among them HA had the best blood clotting activity. This phenomenon could be explained by the facts that HA has a high affinity with plasma proteins such as fibrinogen, and can release $\mathrm{Ca}^{2+}$ to specifically activate prothrombin and coagulation factors to enhance blood clotting [8]. Therefore, HA is recommended as the hemostatic agent for bone defect applications from above 4 pickups.

On the other hand, when compared to chitosan powder, HA showed better clotting activity (Figure 4 ). When chitosan was mixed with HA, its blood clotting activity was comparable to HA instead. This phenomenon could be caused by the combined effects of multiple clotting routes of chitosan and HA. Indeed, chitosan stimulated platelet and erythrocytes aggregation via its amino residue (positively charged surface) [19] and concentrated blood to accelerate clotting via its hydration behavior [20], showing completely different coagulation routes to HA. On the other hand, when HA was coated onto chitosan matrix, the clotting activity was not only depending on the combined effects of chitosan and HA, but also influenced by the amount of blood concentrated by porous scaffold. According to SEM after 7days SBF incubation, HA was successfully deposited to chitosan matrix (Figure 5). Though HA limited the swelling of scaffold (Figure 6a), the BCI index difference between chitosan and HA coated was not significant
(Figure 6b). This observation was suggested to be caused by the increase of HA content $(49 \pm 5 \mathrm{wt} . \%)$ and matrix stiffness [21]. As reported by Qiu et al., increasing substrate stiffness led to increased platelet adhesion, spreading, and platelet activation [22].

In literature, depending on the phosphate source used as well as hydrothermal condition, the morphology of HA can be tailored $[9,23]$. It was reported Inorganic condensed phosphates have a high affinity to $\mathrm{Ca}^{2+}$ ions to form complex in aqueous medium. Under hydrothermal condition, condensed phosphates could be hydrolyzed to release orthophosphate subsequently. Therefore, using $\mathrm{P}_{6} \mathrm{O}_{18}{ }^{6-}$ instead of $\mathrm{PO}_{4}^{3-}$ could result in mesoporous $\mathrm{HA}$, thus changing its clotting activity. The HA-HMP was proved to be HA according to XRD (Figure 7a). And an irregularly shaped and mesoporous morphology was presented (Figure $7 \mathrm{~b}$ ). The increase of surface area enhanced the clotting activity in comparison to regular HA dense particles as expected (Figure 7c).

On the other hand, the HA-1 with significant increase of $\mathrm{Ca} / \mathrm{P}$ in reaction solution resulted in formation of phase impurity and a great increase of blood clotting activity. As seen in XRD, HA-1 displayed characteristics of both HA and brushite $\left(\mathrm{CaHPO}_{4} \cdot 2 \mathrm{H}_{2} \mathrm{O}\right.$, PDF\#090077) (Figure 8a). Consequently, in TEM nanoparticles showed both rod-like and plate-like morphologies (Figure $8 \mathrm{~b}$ ). In the followed BCI test, HA-1 showed much higher blood clotting activity than HA (Figure 8c). It was known fast precipitation of HA caused by strong ionic concentration can induce significant amounts of ions loaded to HA lattice structure [24]. Therefore, in HA-1 a quick release of $\mathrm{Ca}^{2+}$ was expected once in contact with blood to stimulate coagulation cascade. After coagulation, both HA and brushite could induce bone regeneration. This phenomenon provided a possibility to load different ions to HA to help both blood clotting and bone formation. Indeed, different ions such as $\mathrm{Mg}^{2+}, \mathrm{Zn}^{2+}, \mathrm{CO}_{3}^{2-}$ have been doped into $\mathrm{HA}$ to favor bone formation or even provide anti-bacterial property $[25,26]$. However, these ions also showed potential to enhance blood clotting in addition to $\mathrm{Ca}^{2+}$. For example, $\mathrm{Mg}^{2+}$ was observed to enhance coagulant activity of factor IXa [27]; $\mathrm{Zn}^{2+}$ was found to be an important cofactor in regulating platelet aggregation and coagulation [28]; while the presence of $\mathrm{CO}_{3}^{2-}$ in HA could promote blood clotting and protein adsorption [29].

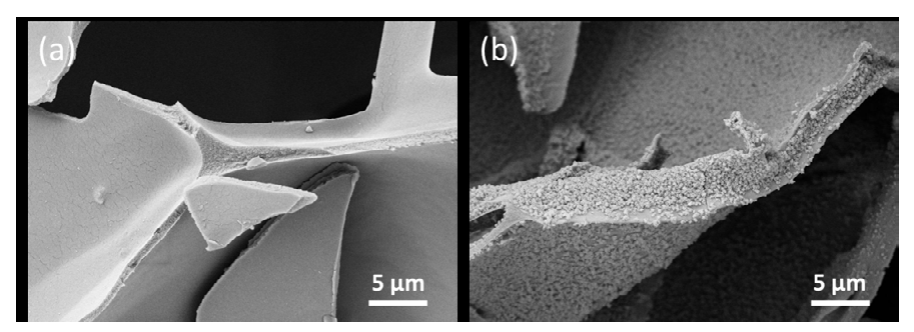

Figure 5. SEM characterization of (a) porous chitosan scaffold; and (b) HA coated chitosan scaffold.

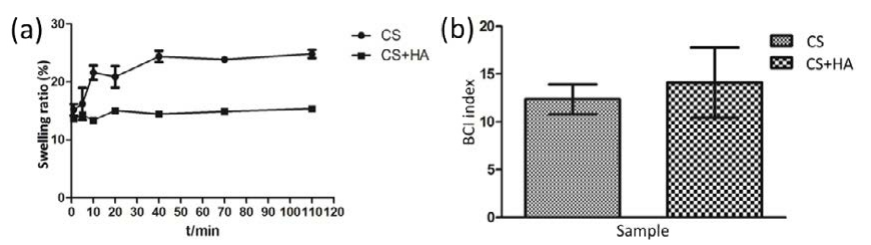

Figure 6. Comparisons between blank and HA coated chitosan scaffolds: (a) swelling ability: and (b) $\mathrm{BCI}$ index results. 

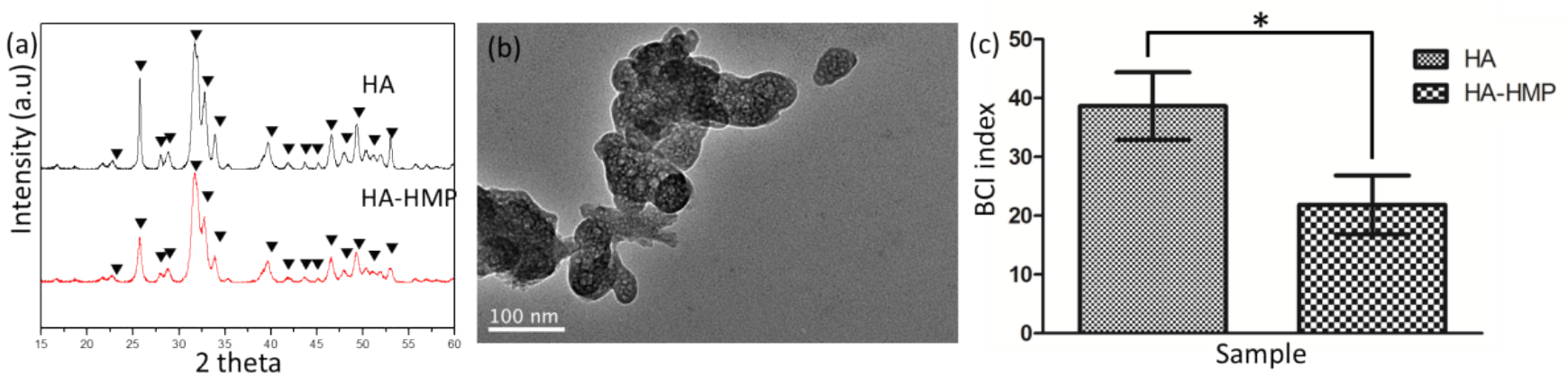

Figure 7. Tests of HA and HA-HMP: (a) XRD of HA and HA-HMP, “『” refers to HA; (b) TEM of HA-HMP; (c) BCI results of HA and HA-HMP, “*” indicates p < 0.05.

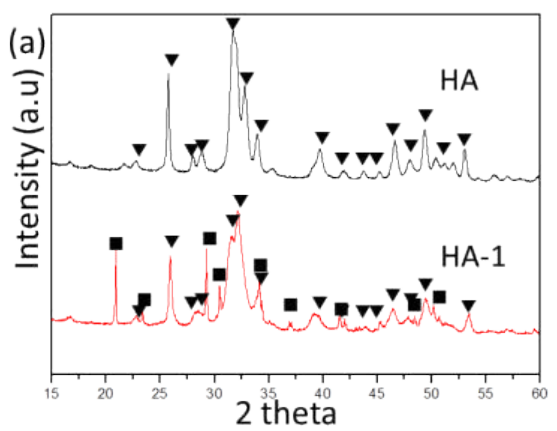

Figure 8. Tests of HA and HA-1: (a) XRD of HA and HA-1, "
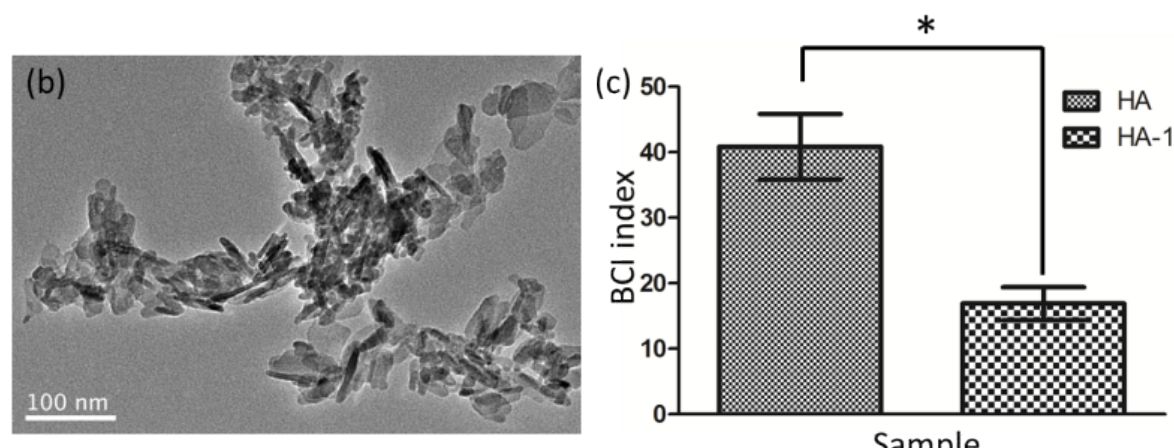

Sample

\section{Conclusion}

In summary, we showed 1) HA is recommended as a potential agent for blood clotting and bone repairing alone or combined with biopolymers; 2) great surface area as well as high amount of active $\mathrm{Ca}^{2+}$ can significantly improve the blood clotting activity of HA. It is wished present work can promote the development of HA based products to replace conventional bone wax.

\section{Acknowledgements}

This work was partially supported by Changzhou Sci \& Tech Program (No. CJ20160040); National Natural Science Foundation of China (No. 11532003); The Natural Science Foundation of Jiangsu Province Research of China (No. BK20151181); High-Level Medical Talents Training Project of Changzhou (No. 2016CZLJ004); The Municipal Social Development Project of the Changzhou (No. CJ20160029).

\section{References}

1. Nooh N, Abdullah WA, Grawish Mel-A, Ramalingam S, Javed F, et al. (2014) The effects of surgicel and bone wax hemostatic agents on bone healing: An experimental study. Indian J Orthop 48: 319-325. [Crossref]

2. Altun I (2016) An Experimental Study of Histopathologic Effects of Hemostatic Agents Used in Spinal Surgery. World Neurosurg 90: 147-153. [Crossref]

3. Pourshahrestani S, Zeimaran E, Djordjevic I, Kadri NA, Towler MR (2016) Inorganic hemostats: The state-of-the-art and recent advances. Mater Sci Eng C Mater Biol Appl 58: 1255-1268. [Crossref]

4. Nemmar A, Albarwani S, Beegam S, Yuvaraju P, Yasin J, et al. (2014) Amorphous silica nanoparticles impair vascular homeostasis and induce systemic inflammation. Int J Nanomed 9: 2779-89. [Crossref]

5. Song L, Sun L, Jiang N, Gan Z (2016) Structural control and hemostatic properties of porous microspheres fabricated by hydroxyapatite-graft-poly (D, L-lactide) nanocomposites. Composites Science and Technology 134: 234-241.

6. Hama C, Umeda T, Musha Y, Koda S, Itatani K (2010) Preparation of novel hemostatic material containing spherical porous hydroxyapatite/alginate granules. Journal of the Ceramic Society of Japan 118: 446-450.

7. Hoffmann B, Volkmer E, Kokott A, Weber M, Hamisch S, et al. (2007) A new biodegradable bone wax substitute with the potential to be used as a bone filling material. Journal of Materials Chemistry 17: 4028-4033.

8. Arimura S, Kawahara K, Biswas KK, Abeyama K, Tabata M, et al. (2007) Hydroxyapatite formed on/in agarose gel induces activation of blood coagulation and platelets aggregation. J Biomed Mater Res B Appl Biomater 81: 456-461. [Crossref]

9. Zhou H, Yang M, Zhang M, Hou S, Kong S, et al. (2016) Preparation of Chinese mystery snail shells derived hydroxyapatite with different morphology using condensed phosphate sources. Ceramics International 42: 16671-16676.

10. Shih MF, Shau MD, Chang MY, Chiou SK, Chang JK, et al. (2006) Platelet adsorption and hemolytic properties of liquid crystal/composite polymers. Int J Pharm 327: 117 125. [Crossref]

11. Zhong C, Chu CC (2012) Biomimetic mineralization of acid polysaccharide-based hydrogels: towards porous 3-dimensional bone-like biocomposites. Journal of Materials Chemistry 22: 6080-6087.

12. Jalota S, Bhaduri SB, Tas AC (2006) Effect of carbonate content and buffer type on calcium phosphate formation in SBF solutions. J Mater Sci Mater Med 17: 697-707. [Crossref]

13. Zhou H, Hou S, Zhang M, Chai H, Liu Y, et al. (2016) Synthesis of B-TCP and CPP containing biphasic calcium phosphates by a robust technique. Ceramics International 42: $11032-11038$

14. Wu CT, Chang J, Fan W (2012) Bioactive mesoporous calcium-silicate nanoparticles with excellent mineralization ability, osteostimulation, drug-delivery and antibacterial properties for filling apex roots of teeth. Journal of Materials Chemistry 22: 1680116809

15. Mohammadi H, Hafezi M, Nezafati N, Heasarki S, Nadernezhad A, et al. (2014) Bioinorganics in Bioactive Calcium Silicate Ceramics for Bone Tissue Repair: Bioactivity and Biological Properties. Journal of Ceramic Science and Technology 5 : 1-12. 
16. Maeda H, Kato K, Kasuga T (2016) Adsorption behavior of proteins on calcium silicate hydrate in Tris and phosphate buffer solutions. Materials Letters 167: 112-114.

17. Wang Z, Zhao YL, Luo Y, Wang SG, Shen MW, et al. (2015) Attapulgite-doped electrospun poly (lactic-co-glycolic acid) nanofibers enable enhanced osteogenic differentiation of human mesenchymal stem cells. RSC Advances 5: 2383-2391.

18. Kudela D, Smith SA, May-Masnou A, Braun GB, Pallaoro A, et al. (2015) Clotting Activity of Polyphosphate-Functionalized Silica Nanoparticles. Angew Chem Int Ed Engl 54: 4018-4022. [Crossref]

19. Okamoto Y, Yano R, Miyatake K, Tomohiro I, Shigemasa Y, et al. (2003) Effects of chitin and chitosan on blood coagulation. Carbohydrate Polymers 53: 337-342.

20. Wu S, Huang Z, Yue J, Liu D, Wang T, et al. (2015) The efficient hemostatic effect of Antarctic krill chitosan is related to its hydration property. Carbohydr Polym 132: 295-303. [Crossref]

21. Caridade SG, Merino EG, Alves NM, Mano JF (2013) Biomineralization in chitosan/ Bioglass ${ }^{\circledR}$ composite membranes under different dynamic mechanical conditions. Mater Sci Eng C Mater Biol Appl 33: 4480-4483. [Crossref]

22. Qiu YZ, Brown AC, Myers DR, Sakurai Y, Mannino RG, et al. (2014) Platelet mechanosensing of substrate stiffness during clot formation mediates adhesion, spreading, and activation. Proc Natl Acad Sci U S A 111: 14430-14435. [Crossref]

23. Qi C, Zhu YJ, Sun TW, Wu J, Chen F (2015) Microwave-Assisted Hydrothermal
Rapid Synthesis of Amorphous Calcium Phosphate Mesoporous Microspheres Using Adenosine 5 '-Diphosphate and Application in pH-Responsive Drug Delivery. Chem Asian J 10: 2503-2511. [Crossref]

24. Tas AC, Bhaduri SB (2004) Rapid coating of Ti6A14V at room temperature with a calcium phosphate solution similar to 10x simulated body fluid. J. Mater. Res.19: 27422749.

25. Ahmadzadeh E, Talebnia F, Tabatabaei M, Ahmadzadeh H, Mostaghaci B (2016) Osteoconductive composite graft based on bacterial synthesized hydroxyapatite nanoparticles doped with different ions: From synthesis to in vivo studies. Nanomedicine 12: 1387-1395. [Crossref]

26. Swetha M, Sahithi K, Moorthi A, Saranya N, Saravanan S, et al. (2012) Synthesis, Characterization, and Antimicrobial Activity of Nano-Hydroxyapatite-Zinc for Bone Tissue Engineering Applications. J Nanosci Nanotechnol 12: 167-172. [Crossref]

27. Morita T, Yoshida M, Yamashita T, Sekiya F (1997) A new cascade theory of blood coagulation: Magnesium (II) is a crucial constituent of the blood coagulation cascade. Thromb. Haemost. P1755.

28. Vu TT, Fredenburgh JC, Weitz JI (2013) Zinc: an important cofactor in haemostasis and thrombosis. Thromb Haemost 109: 421-430. [Crossref]

29. Takemoto S, Kusudo Y, Tsuru K, Hayakawa S, Osaka A, et al. (2004) Selective protein adsorption and blood compatibility of hydroxy-carbonate apatites. J Biomed Mater Res A 69: 544-551. [Crossref]

Copyright: (C2017 Yang Y. This is an open-access article distributed under the terms of the Creative Commons Attribution License, which permits unrestricted use, distribution, and reproduction in any medium, provided the original author and source are credited. 